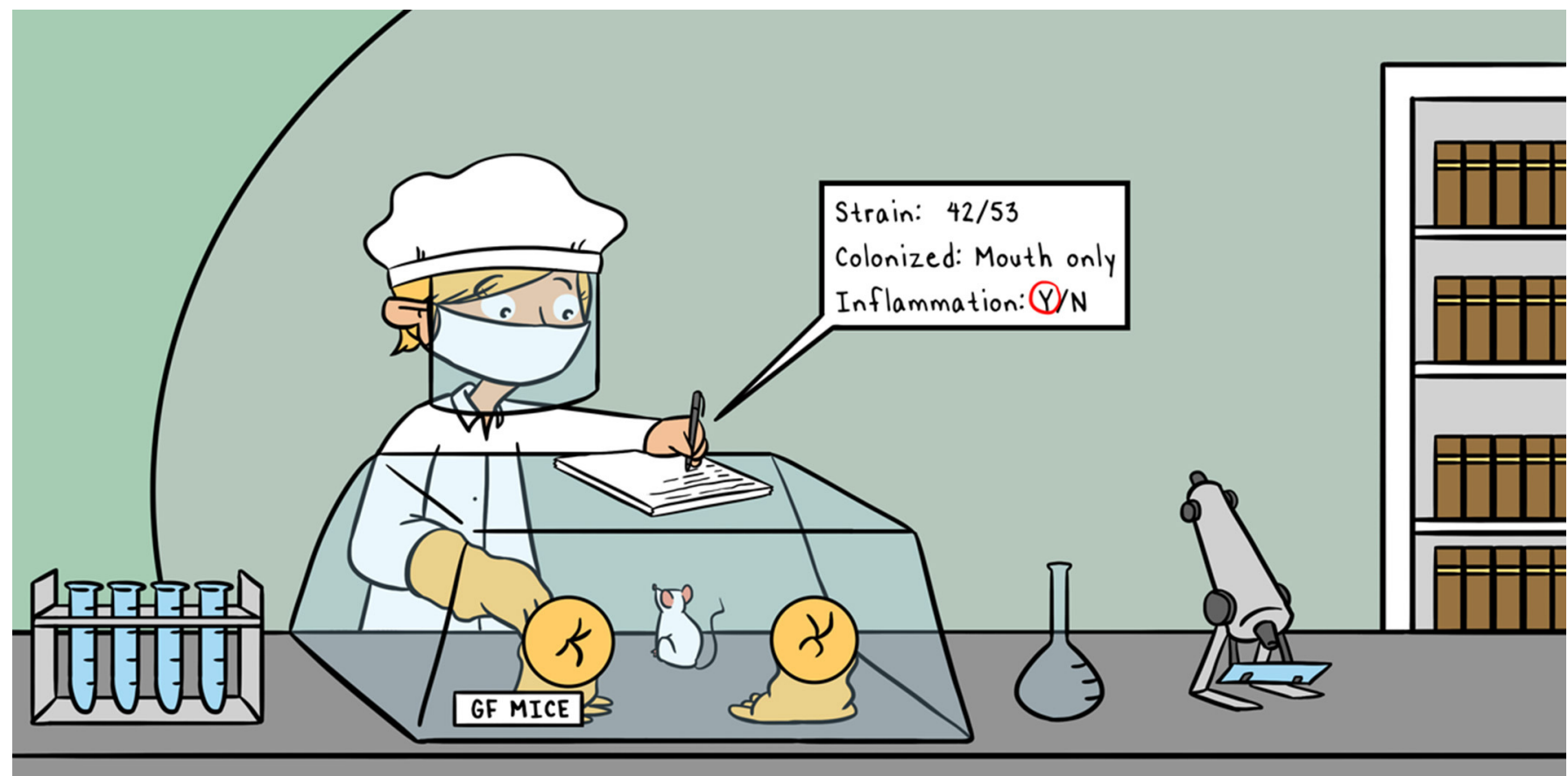

\title{
HOW DO GUT BACTERIA REGULATE OUR IMMUNE SYSTEM?
}

\section{Dana Kadosh and Naama Geva-Zatorsky*}

The Ruth and Bruce Rappaport Faculty of Medicine, Technion, Haifa, Israel

\section{YOUNG REVIEWERS}

THE LEO

BAECK

EDUCATION

(3)

(2)
CENTER

MIDDLE

SCHOOL

AGES: $12-13$
When we think about bacteria, we often think first about disease. While there are many bacteria that cause diseases, there are also many other bacteria that are useful for human health. The human body has an enormous number of these good bacteria, which work together and with the immune system to protect us against diseases. In this article, we will discuss this relationship between the good bacteria living inside us and the immune system. We will explain how we can study these helpful bacteria, and describe the tools and methods at our disposal, such as special mice whose bodies do not contain any bacteria. Finally, we will describe how we can use the good bacteria living in the human body to advance medicine and drug development. 


\section{MICROBIOTA}

The entirety of microorganisms (bacteria, viruses, fungi, and other tiny creatures) colonizing the body. The microbiota is present mostly in mucosal tissues, the digestive system, and skin.

\section{PATHOGENS}

Disease-causing organisms, such as bacteria.

\section{SYMBIONTS}

Friendly bacteria living with us in co-existence and cooperation, from which both of us are contributed.

\section{MODEL ORGANISM}

An animal used for experiments which is easy to grow and study. Experimental results in a model organism serve as a basis for understanding the human body and its function.

\section{THE IMMUNE AND DIGESTIVE SYSTEMS: IS THERE A RELATIONSHIP BETWEEN THEM?}

Bacteria are tiny living creatures, smaller than the cells of the human body. Inside the intestines of humans and many other animals, there are many kinds of microorganisms, including many different bacteria. Together, this diverse ecosystem of microorganisms is called the microbiota. The initial exposure of a baby to bacteria occurs in the birth canal during a natural birth, or from the mother's skin during a Cesarean section. After birth, we get the bacteria that make up the microbiota mostly from what we eat and drink. Thus, most of the human microbiota lives in the digestive system.

In all areas of the body, including the intestines, cells of the immune system are present. The immune system is a complex system, responsible for protecting us against harmful invaders called pathogens. The immune system has two components. One component of the immune system acts very quickly and responds non-specifically, meaning it responds basically the same way, no matter what kind of foreign invader enters the body. The second component responds more slowly, but in a stronger way that is uniquely tailored to each specific pathogen. This component has immunological memory, which means it can remember the pathogens it sees and, if the same pathogen invades again, a quicker and stronger response will occur to fight it off. The immune system is spread throughout the body-from the bone marrow, where the various types of white blood cells (immune cells) are produced; to the lymphatic system, which transports immune cells to and from the blood stream and from there to the rest of the body; to the immune cells present in the body's organs, such as the skin, the lungs, and even the brain. Inside the digestive system there is a whole wonderous world of the immune system.

In our research, we studied the relationship between the immune system and the microbiota in the digestive system. The job of the immune system is to protect us against harmful pathogens and to fight them until they are removed from the body. But on the other hand, the immune system manages to peacefully co-exist with the good bacteria of the microbiota, the symbionts, and even to benefit from them. How does the immune system do this?

\section{THE INFLUENCE OF BACTERIA ON THE IMMUNE SYSTEM-RESEARCH ON MICE}

Our research was performed using mice, which are much easier to study than humans. These mice are called model organisms. Although mice are small, they are similar to humans with respect to genetics, body structure, and behavior, and it is helpful to learn about and improve human health based on mice studies. To investigate the 
Figure 1

Germ-free mice must be grown in an isolated environment, in which the air, food, and water are free of bacteria. (A) A colony of mice grows and develops inside an isolator, a system that is protected from the external environment. The isolator contains a pair of internal, clean gloves, into which a researcher's hands can be inserted from the outside, to take care of the mice. Inside the isolator, mice live in cages. (B) An enlargement of one of the cages from inside the isolator.

\section{ISOLATOR}

An isolated habitat without bacteria.
A B

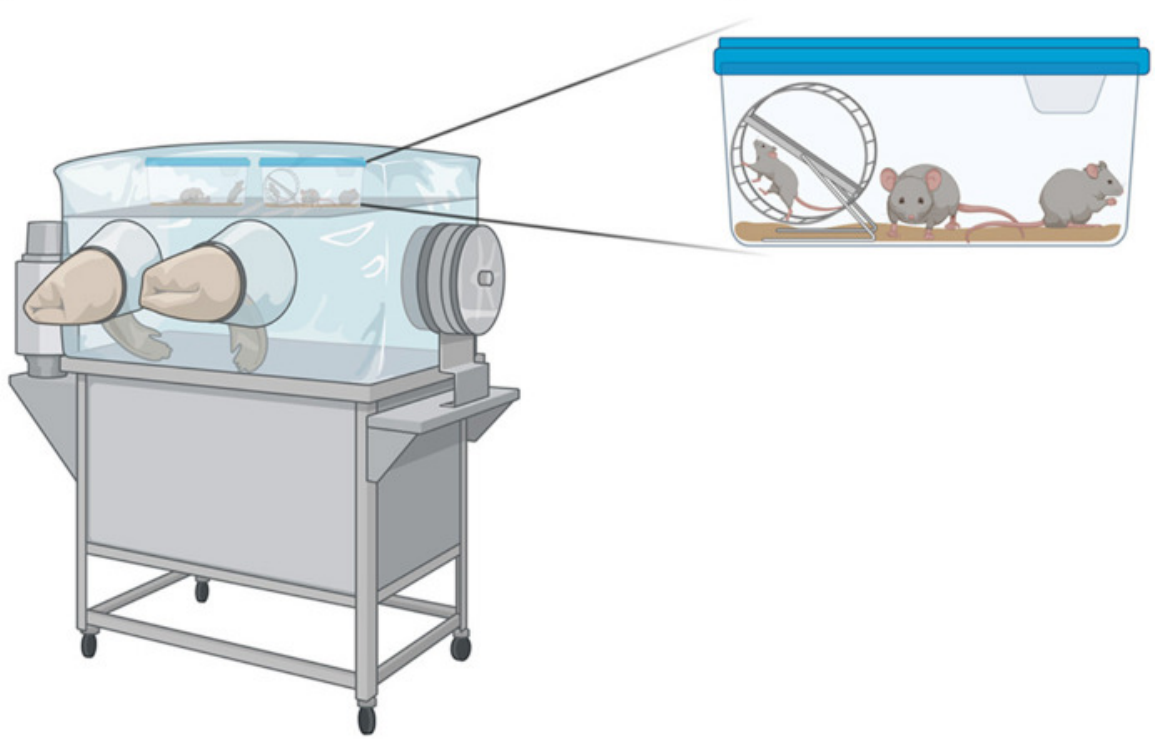

Figure 1

effects of a specific type of bacteria on the immune system of mice, special mice called germ-free mice (GF mice) are used. GF mice need a particularly clean and isolated growing area, since germs are everywhere-in soil, on objects, in food, and in water. GF mice are born by Cesarean section (to avoid bacteria from their mothers' reproductive tracts) in an extremely clean environment (without germs), and they are immediately moved into a clean and isolated environment where they can grow up-a system called an isolator. The food and water that GF mice receive goes through a process of sterilization. Food and water are heated to $121^{\circ} \mathrm{C}$ at high pressure, which destroys all the living bacteria. The air that GF mice breathe goes through a filtration process that filters out the germs, which are often carried through the air or on dust particles. GF mice live in this isolated environment, grow up without any germs, reproduce naturally, and produce an entire colony of GF mice (Figure 1).

To test the influence of one type of bacteria at a time on the immune system, one specific strain of bacteria was inserted directly into the digestive system of each mouse, under germ-free conditions. The mice that received the bacteria were removed from the rest of the colony and allowed to grow in a separate GF cage. This prevented the mice that got the bacteria from infecting all the other mice in the colony! Bacteria pass easily between mice living in the same cage, through physical contact or through eating each other's feces (a known characteristic in mice behavior). Bacteria from the feces can grow and thrive in the digestive systems of the mice that ate them. 
HOST

Gives temporary residence. A host can be a person, animal, or plant that carries microorganisms on or inside its body, and provides them with nutrients, shelter and other needs.

\section{INFLAMMATORY} RESPONSE

The response of the body's immune system against to harmful stimuli. Its purpose is to create optimal conditions for the body to deal with a foreign invader
This process of isolation and clean work provided us with a system in which we could study the influence of one specific strain of bacterium at a time on the immune system of the host mice in which the bacteria live and grow. We should note that the immune systems of GF mice are not as developed as those of normal mice, functioning less well and leaving the mice more sensitive to diseases. This happens because GF mice grow and develop without any bacteria around. Recent studies have shown that bacteria in general, and gut bacteria specifically, serve an important role in the proper development of the immune system.

\section{BACTERIA CAN SPEED UP OR SLOW DOWN THE ACTIVITY OF THE IMMUNE SYSTEM}

In our research, we tested 53 different strains of bacteria that naturally inhabit the digestive system of humans. It is interesting to know that some strains of bacteria were found only in the mouth area, some in the stomach (despite its high acidity), and most in the small and large intestines. Because we used GF mice, the bacteria we added had no competition with other types of bacteria, they could "choose" their favorite place to live. Bacteria seem to make this choice based on the physical and chemical characteristics (like acidity or the availability of certain types of food) that they prefer to live in.

We also found that each type of bacteria affected the immune system in a specific way, meaning that the immune system responded differently to the presence of each type of bacteria. There were also some types of bacteria that the immune system responded to in the same way, even though those types of bacteria were only distantly related to each other. Some types of bacteria activated special cells of the immune system to release substances that cause an inflammatory response in the intestines, for example, while other bacteria stimulated the activity of special control cells of the immune system, which balance the immune response, so it does not get out of control (Figure 2).

It is important to understand that inflammation is a response of the immune system-our bodies produce inflammation because inflammatory conditions help the body to fight off the foreign invader. Sometimes, when the inflammatory response is too strong, it can lead to the development of inflammatory diseases, including Crohn's disease and colitis, which result from inflammation of the intestines. So, it is important for the immune system to have a balance of cells-some that stimulate inflammation and some that calm it down. The communication between the bacteria and the immune system is important for regulating the activity of the immune system, to prevent diseases related to improper immune system functioning. Think of how bacteria could potentially benefit people who have inflammatory intestinal diseases-maybe, if they receive the right kind of bacterial 
Figure 2

One type of bacteria is introduced to the immune system through the mouth of mice. As the bacteria move through the digestive system, they find the spot with the perfect living conditions. Bacteria can activate various cells of the immune system directly (as the blue cell), or through regulatory cells (the "policeman" cell) that make some immune cells more active (like the green cell) and other cells less active (like the red cell). This is how bacteria can help to balance the activation and performance of the immune system.

IMMUNOMODULATORY MOLECULES

Substances with the ability to change and regulate (modulate) the immune system, the system that defends us from diseases and keeps us healthy.

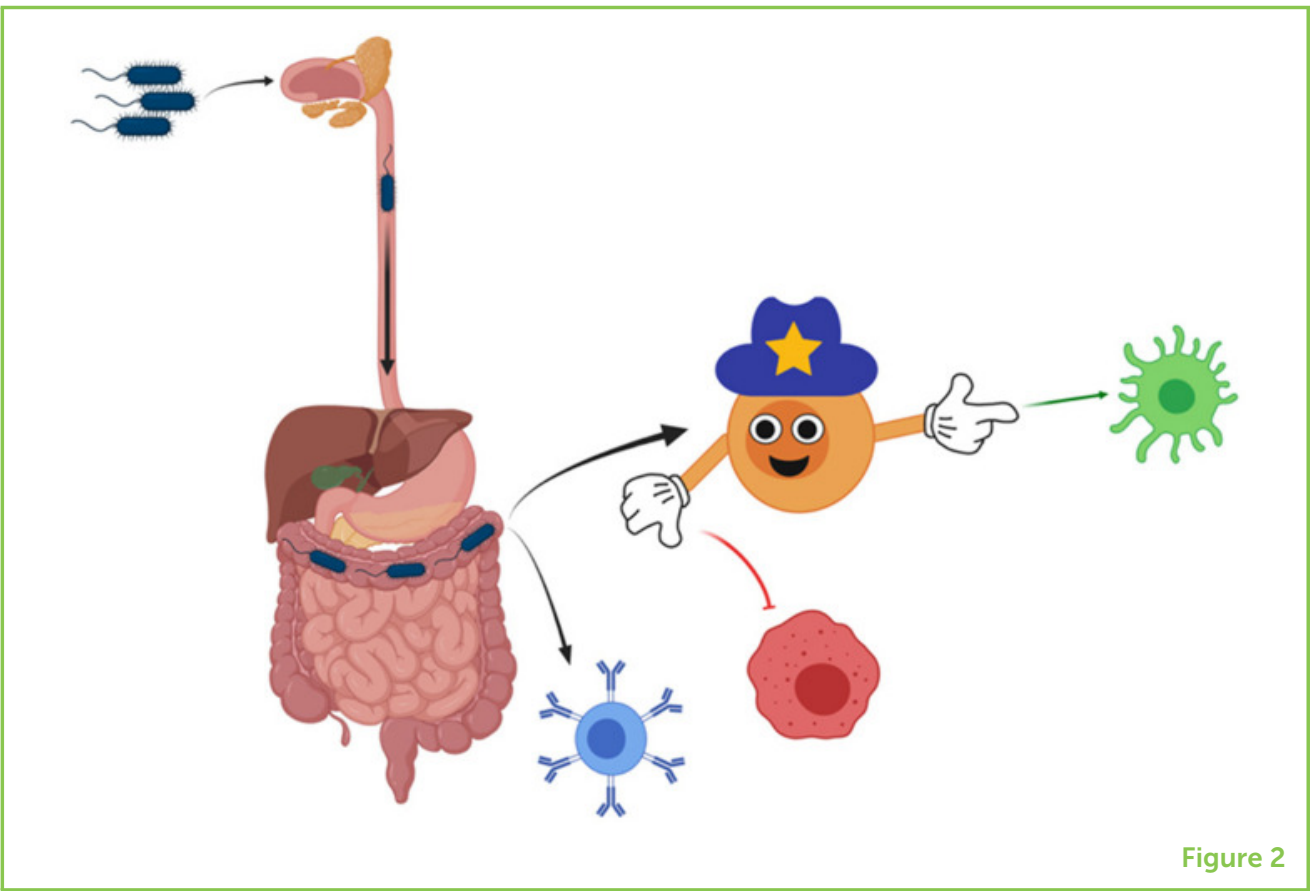

product, those bacteria could balance their inflammation level, and maybe even cure them completely!

\section{HOW DO BACTERIA COMMUNICATE WITH THE IMMUNE SYSTEM?}

Generally, bacteria interact with the immune system through proteins present on their surfaces that are recognized by the immune system. Some bacteria also release substances that influence our immune cells, increasing or decreasing the numbers of these cells, or changing the way the immune cells function. The substances that can influence the immune system are called immunomodulatory molecules.

Much research is still ahead of us, but once we can fully characterize these immunomodulatory molecules, they could serve as medicines in the future. For example, a person who has an inflammatory intestinal disease might be cured by taking a medicine containing immunomodulatory molecules that can calm the inflammation. Isn't it cool that bacteria are the sources of these potential medicines? The beneficial influence of bacterial immunomodulatory molecules is not limited to the intestines. These substances could influence the whole body, helping to treat diseases in various organs (Figure 3).

\section{SUMMARY}

Within the digestive system lies a treasure trove of bacteria that benefit the immune system-and we hope to keep discovering more of them! Each type of bacteria has a different influence on the 
Figure 3

The process of producing immunomodulatory molecules that could regulate the immune system starts with growing bacteria. Then, laboratory processes are used to isolate the immunomodulatory molecules from the bacterial solution. The molecules are packaged inside pills that can be swallowed. Patients with certain diseases, such as those caused by uncontrolled inflammation, can take the appropriate pills and may be cured.

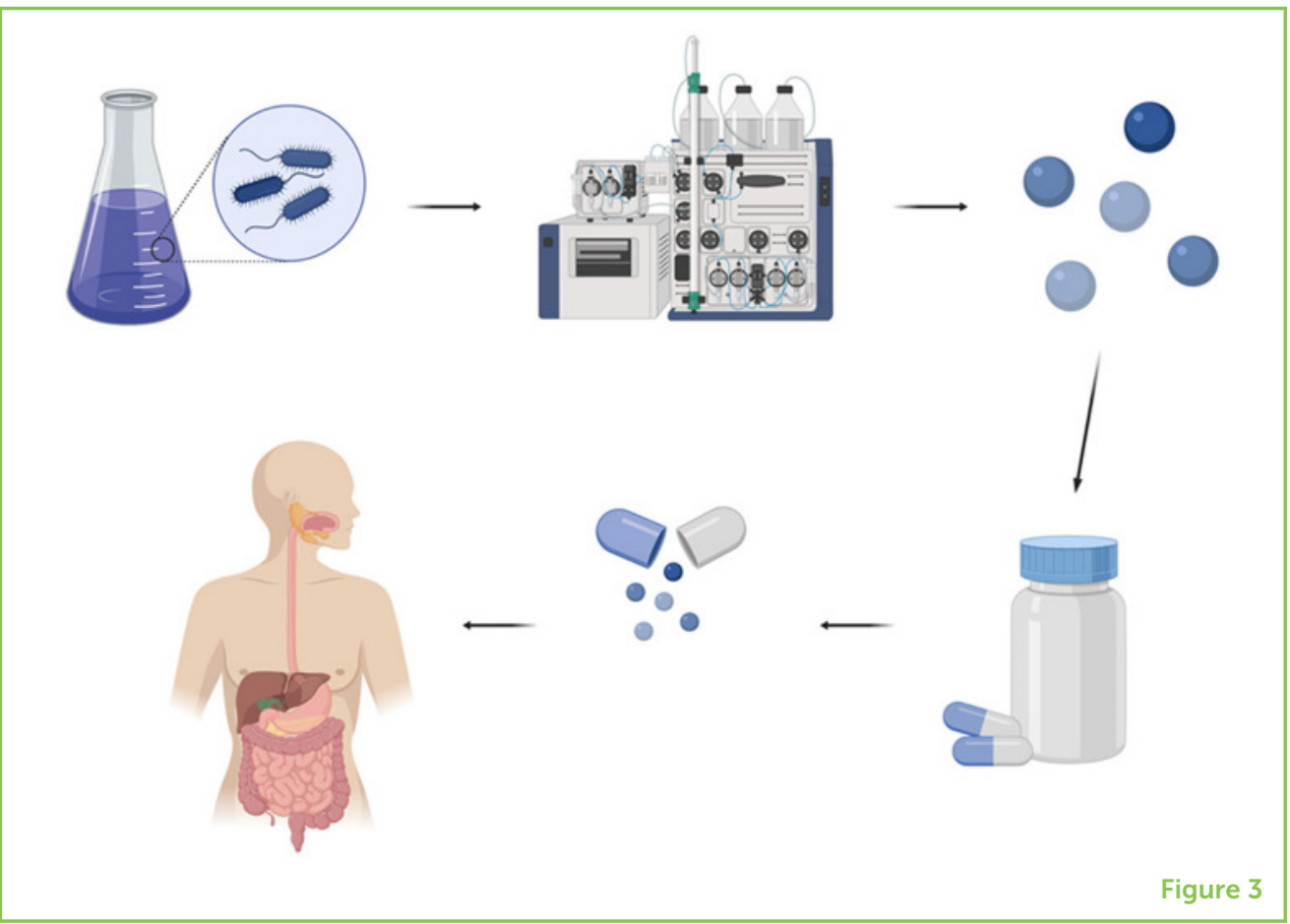

immune system, and when many types of bacteria are present together in the digestive system, they create a balance that contributes to our health. These bacteria come from the foods we eat and the environments we live in, and once in the gut, they secrete immunomodulatory molecules that either enhance or decrease the activity of the immune system. Once they are better characterized, some of these immunomodulatory molecules could be used as medicines to treat various diseases, including colitis, Crohn's disease, and rheumatoid arthritis. To summarize, it is good to know that we have good bacteria in our guts which help us to stay healthy, and that further research on these bacteria could, in the future, help to make many people with disorders of the immune system become healthier, too!

\section{ACKNOWLEDGMENTS}

We thank Lilach Elbaum and Tal Gefen for their reading, proofing, and significant additions, and thank you to all the Geva-Zatorsky lab for interesting discussions and reserch on microbiota. Special thanks to the Kasper and Benoist and Mathis labs, and especially to Esen Sefik, Lindsay Kua, Tze Tan, Adriana Ortiz-Lopez, Lesley Pasman, Tsering Yanortsang, Liang Yang, and Ray Jupp for joint research with Dr. Geva-Zatorsky, during her post doctorate studies upon which this paper is based. Figures in this paper were illustrated using BioRender.com. 


\section{ORIGINAL SOURCE ARTICLE}

Geva-Zatorsky, N., Sefik, E., Kua, L., Pasman, L., Tan, T. G., Ortiz-Lopez, A., et al. (2017). Mining the human gut microbiota for immunomodulatory organisms. Cell 168, 928-943.e11. doi: 10.1016/ j.cell.2017.01.022

SUBMITTED: 06 June 2021; ACCEPTED: 10 June 2021;

PUBLISHED ONLINE: 15 July 2021.

EDITED BY: Idan Segev, Hebrew University of Jerusalem, Israel

CITATION: Kadosh D and Geva-Zatorsky N (2021) How Do Gut Bacteria Regulate Our Immune System? Front. Young Minds 9:721325. doi: 10.3389/frym.2021. 721325

CONFLICT OF INTEREST: The authors declare that the research was conducted in the absence of any commercial or financial relationships that could be construed as a potential conflict of interest.

COPYRIGHT () 2021 Kadosh and Geva-Zatorsky. This is an open-access article distributed under the terms of the Creative Commons Attribution License (CC BY). The use, distribution or reproduction in other forums is permitted, provided the original author(s) and the copyright owner(s) are credited and that the original publication in this journal is cited, in accordance with accepted academic practice. No use, distribution or reproduction is permitted which does not comply with these terms.

\section{YOUNG REVIEWERS}

\section{THE LEO BAECK EDUCATION CENTER MIDDLE SCHOOL, AGES: 12-13}

We are students in 7th grade, class number 4 in the Leo Back Middle School in Haifa. We study in the gifted course from the basic classes. This year, we started learning in middle school and new students joined us. We love science, music, and art, and enjoy combining these subjects.

\section{AUTHORS}

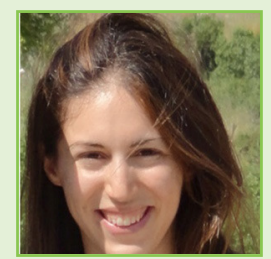

\section{DANA KADOSH}

I am a biotechnology and food engineer, and a master's student in the Faculty of Medicine at the Technion, in the lab of Prof. Naama Geva-Zatorsky. In the lab, we study the mutual relationship between gut bacteria and the immune system. My research focuses on bacteriophages, viruses which infect bacteria, and their direct influence on the body. I enjoy teaching science through experiential demonstrations at science centers for kids and youth. I love to dance, travel in nature, and play board games and in escape rooms. 


\section{NAAMA GEVA-ZATORSKY}

Professor Naama Geva-Zatorsky is a researcher at the Technion, at the Rapaport Faculty of Medicine. She completed her double bachelor's degree in chemistry and biology at Tel Aviv University. She completed master's and Ph.D. degrees with honors at the Weizmann Institute, in system biology. She continued her post-doctorate studies at the Harvard School of Medicine. With her research group at the Technion, she studies the interactions of gut microbiota with the physiology of the mammal host, in health and disease. Her lab studies how gut bacteria could complete the human physiology and promote health. *naama_gz@technion.ac.il 